\title{
The effect of transactional analysis on the self-esteem of imprisoned women: a clinical trial
}

\author{
Mahya Torkaman ${ }^{1}$, Jamileh Farokhzadian², Sakineh Miri ${ }^{3^{*}}$ and Batool Pouraboli ${ }^{4}$
}

\begin{abstract}
Background: The imprisoned women usually have low self-esteem and suffer from various physical and mental complaints; they may suffer from feelings of emptiness, isolation, and depression. Transactional analysis (TA) is part of a comprehensive system attributed to the individual and social psychiatry for personal development of selfesteem among the imprisoned women. Therefore, the present study aimed to investigate the effect of TA grouptraining on the self-esteem of imprisoned women.

Methods: This clinical trial was conducted among the imprisoned women in a prison in Southeastern Iran using pretest-posttest design. In this regard, 76 women were randomly allocated to the intervention $(n=35)$ and control $(n=41)$ groups. The TA group-training program was held for eight 90 -min sessions for the intervention group. Data were collected using a demographic questionnaire and the Rosenberg's self-esteem scale (RSES). Later, all participants were evaluated before and 1 month after the intervention.
\end{abstract}

Results: In pre-test, the mean scores of self-esteem were $11.8 \pm 4.67$ and $7.97 \pm 4.52$ for the intervention and control groups, respectively. These scores showed low levels of self-esteem and the difference between the two groups was significant ( $p=0.001, t=-3.61$ ). In the post-test, the mean scores of self-esteem improved to the moderate level $(22 \pm 2.52)$ in the intervention group compared to the control group $(8.92 \pm 4.04)$. This indicates the significant improvement of self-esteem in the intervention group ( $p=0.001, t=17.15)$.

Conclusions: The results showed that TA group-training had a significant effect on self-esteem. Therefore, the experienced and expert counselors and psychologists are recommended to hold transactional analysis grouptraining courses to enhance self-esteem among women prisoners.

Trial registration: Iranian Registry of Clinical Trials, IRCT20170725035289N5 Date registered: 25/08/2018.

Keywords: Group training, Transactional analysis, Self-esteem, Imprisoned women

\section{Background}

Considering the rapid increase in the number of women prisoners, many studies have been conducted to understand their unique needs. The results of these studies showed that the pathway to prison differs between men and women [1].However, the low number of imprisoned women has led the authorities to neglect the problems and difficulties of these women; so, imprisoned women

\footnotetext{
* Correspondence: miri.education@gmail.com; s_miri@kmu.ac.ir ${ }^{3}$ Department of Psychiatric Nursing, School of Nursing and Midwifery, Kerman University of Medical Sciences, Haft-Bagh Highway, PO Box: 7716913555, Kerman, Iran

Full list of author information is available at the end of the article
}

were put on the second rank of importance [2]. Women are often integral to families and the community health depends on them to a large degree, but many of them are faced with numerous unsolved problems and conflicts. Consequently, women's misbehaviors and faults can threaten the stability and firmness of families [1]. Therefore, the self-confidence and mental aspect of the criminals, especially imprisoned women should be improved, so that they can restart a new and happy life after their imprisonment [3].

Self-esteem is a psychological concept that refers to an individual's self-evaluation and indicates the extent to which people evaluate themselves as capable and worthy 
$[4,5]$. In other words, self-esteem is defined as individuals' subjective emotional response towards themselves [6]. Psychologists usually define self-esteem as an enduring personality characteristic with possibly normal shortterm variations. Self-esteem is a concept of personality [7]. In order to develop self-esteem, a sense of self-worth is required, which is achieved by embracing challenges that result in success [8].

High or low self-esteem causes numerous positive and negative effects on humans. Individuals with high selfesteem are always dutiful and responsible; such characteristics are created as the consequence of awareness about one's actions and behaviors [9]. On the other hand, individuals with low self-esteem ignore their goals much more easily and move through the direction determined by others [7]. Self-esteem is an important factor for the individual's progress and success throughout life. Individuals with positive evaluation of their characteristics have different great goals. They are also empowered with more enthusiasm and eagerness to face new successes [10]. Therefore, individuals' "self-interpretation and ego state" can be considered as an effective factor in their self-esteem. In this regard, TA is introduced as a useful therapeutic approach for individuals with low self-esteem [11].

Eric Berne, the founder of TA, indicated that individuals manifest certain sets of thoughts, feelings, and behaviors at different situations [12]. Berne called these three sets as "Ego States" of Child, Adult, and Parent. Due to the fact that each state of Ego is considered as one of the sub-constructs of ego, each state would be adjusted and adapted if used in an appropriate situation [13]. Each Ego-state is characterized by a particular set of beliefs, emotions, and behavior responsible for social interactions [11]. The Ego-Child state is characterized by impulsivity, emotionality, expressivity, irrational behavior, and a self-centered attitude. The Ego-Parent state is characterized by a set of values, norms, orders, prohibitions, and obligations [14]. The Ego-Adult state is characterized by mostly logical constructive conditioning. This state is responsible for the reality analysis, estimation of the possible solutions, rational decision makings, and assertive relationship of the individual with others [15]. The literature showed that TA group-training method was an effective method in helping people to communicate and interact with other individuals [16]. In general, TA has been used to increase self-esteem [11], help anxious and abused women [17], and treat personality disorders [14]. Furthermore, it has been widely applied in clinical and therapeutic affairs [15], developmental psychology [18], and management communication of personality, behaviors, and relationships $[15,16$, 19]. Although TA is one of the most effective psychological theories, it has not been considered much by the researchers [18]. Techniques of TA were designed to promote the independence and self-direction using one's knowledge, self-motivation, and resources as an adult to solve problems $[16,20]$. The effectiveness of TA training on self-esteem was confirmed in some studies [15]. In Yugoslavia, a study over the alcohol and non-alcohol addicts indicated that the TA group-training had a positive effect on the psycho-emotional state of the alcohol addicts [14]. A research in Iran showed that addicted women had a low level of self-esteem, which hindered them from changes and reforms in life. The findings of the mentioned study recommended TA to improve selfesteem of the addicted imprisoned women [6]. Another study in Iran was carried out by Forghani et al. They reported that TA had a significant impact on the addicts and prevented addiction recurrence by enhancing the participants' coping skills and mental functions [21].

The studies mentioned above were conducted to investigate the effect of TA on the self-esteem or other psychological characteristics of individuals. Women, as the main members of the society and family, have been neglected most of the time. To the best of our knowledge, the effect of TA group-training on the self-esteem of Iranian imprisoned women has not been investigated. Therefore, the present study was conducted to deal with the issue.

\section{Methods \\ Study design \& setting}

This pretest-posttest randomized clinical trial was conducted in the Southeast of Iran. In the prisons of Iran, monitored by the prison-related organizations of each province, different specialists work, such as psychologists and psychiatrists to help the prisoners. Sports classes are also held by the authorities. According to the rules, imprisoned women can meet their families on certain days of week and in some crimes, they can have some leaves per in the month.

\section{Samples}

The target population of this study included al the imprisoned women at the time of data collection $(N=$ 120). The study participants were 84 imprisoned women selected according to the inclusion criteria. The participants were randomly allocated to the intervention and control groups (42 participants in each group). The inclusion criteria of this study recruited the prisoners who were in prison for at least 6 months, whose jail sentences were up to the end of study, and who had at least elementary education. The exclusion criteria consisted of failure to complete the questionnaires due to any reasons and failure to attend the training sessions for more than one session. In total, 35 questionnaires in the 
intervention and 41 questionnaires in the control groups were collected and analyzed.

\section{Instrument and data collection}

Data were collected using two questionnaires. The first one was a demographic questionnaire and the second one was the 10-item Rosenberg Self-Esteem Scale (RSES) developed in 1965. This scale evaluates the individual's overall self-image. Each item in RSES is scored based on a four-point Likert scale including 'totally agree' (3 scores), 'agree' (2 scores), 'disagree' (1 score), and 'totally disagree' ( 0 score). The negative items (items from 6 to 10) were scored inversely. In RSES, higher scores indicate higher self-esteem levels and the attainable scores range from zero to 30. Additionally, low, moderate, and high levels of self-esteem are indicated by scores lower than 15, 15-25, and higher than 25, respectively. The Cronbach's alpha for the original scale was measured as $74 \%$ [22, 23] (Additional file 1). In a study by Rajabi et al., the internal consistency coefficient of the Persian version of the scale was calculated as $84 \%$ for the entire sample of students, $87 \%$ for the male students, and $80 \%$ for the female students. The correlation coefficients between the score of each item and the total score varied from 56 to $72 \%$, which were significant at $P<0.001$. The construct validity of the scale was measured using factor analysis. Moreover, a negative and significant relationship was observed between this scale and the Death Obsession Scale (DOS) with a coefficient of -0.34 for the entire sample, -0.44 for the male students, and -0.27 for the female students. This suggests the good validity of the Rosenberg's Self-Esteem Scale [24].

\section{Intervention procedure}

Initially, the experimental group was divided into three sub-groups (14 participants in each). Then, sub-each group attended the TA training program in eight 90min sessions weekly. The TA trainings were presented by the first researcher, a psychologist, a nursing $\mathrm{PhD}$, and a psychiatric nurse using educational slides, lectures, group discussions, as well as questions and answers. The control group received no training during the study period. Table 1 represents the topics presented during the training sessions [25].

\section{Statistical analysis}

Data were analyzed using SPSS (version 20) and by running descriptive (percentage, mean, and standard deviation) and analytical statistics (chi-squared test, independent samples $t$-test, and paired-samples $t$-test and ANCOVA). According to the results of Kolmogorov-Smirnov test, data enjoyed a normal distribution. The level of significance was set at $P \leq 0.05$.

\section{Results}

\section{Demographic information}

The results showed that the majority of participants were housewives in the age range of 21-40 years and experienced their first prison sentence. Most participants had elementary education, were married, and were prisoned for 3 years. According to the chi-squared test, no significant difference was observed between the intervention and control groups in terms of the demographic information (Table 2).

\section{Self esteem}

In the pre-test stage, the mean score of self-esteem in the intervention group $(11.8 \pm 4.67)$ was higher than that of the control group $(7.97 \pm 4.52)$ and the difference between the two groups was significant $(p=0.001, t=$ -3.61 ). However, the results showed that the level of self-esteem was low for both groups. In the post-test

Table 1 Training program

\begin{tabular}{|c|c|}
\hline Session 1: & $\begin{array}{l}\text { Establishing initial communication, Introducing members to each other, } \\
\text { and clarifying the study purpose }\end{array}$ \\
\hline Session 2: & $\begin{array}{l}\text { Introducing the initial concepts of the structural analysis: "parent", "adult ", } \\
\text { and "child". }\end{array}$ \\
\hline Session 3: & $\begin{array}{l}\text { Getting acquainted with the concept of mutual communication: direct transaction, } \\
\text { crossed transaction, and ulterior transaction. }\end{array}$ \\
\hline Session 4: & $\begin{array}{l}\text { Strengthening the "adult" and controling the negative aspects of the "parent", } \\
\text { especially the "critical parent". }\end{array}$ \\
\hline Session 5: & $\begin{array}{l}\text { Explaining about the personality illnesses, providing various examples, and considering } \\
\text { the interpersonal exchanges. }\end{array}$ \\
\hline Session 6: & Explaining time management using different methods. \\
\hline Session 7: & $\begin{array}{l}\text { Life minute analysis: Discussing the life formation process, omitting the undesirable events in } \\
\text { life, and making decisions applying the "Adult". }\end{array}$ \\
\hline Session 8: & $\begin{array}{l}\text { Making healthy relationships with others and adjustments to different situations. Increasing intimacy, } \\
\text { adopting a healthy state of life, and having conscious control of the Ego states. Discussing and making } \\
\text { conclusions about the subject. }\end{array}$ \\
\hline
\end{tabular}


Table 2 Comparison of the demographic information between the intervention and control groups

\begin{tabular}{|c|c|c|c|c|c|c|c|}
\hline \multirow[t]{2}{*}{ Variables } & \multirow[t]{2}{*}{ Groups } & \multicolumn{2}{|c|}{ Intervention } & \multicolumn{2}{|c|}{ Control } & \multirow[t]{2}{*}{$x^{2}$} & \multirow[t]{2}{*}{$P$} \\
\hline & & $n$ & & $\mathrm{~N}$ & & & \\
\hline \multirow[t]{4}{*}{ Occupation } & Housekeeper & 35 & 100 & 41 & 92.70 & 2.66 & 0.446 \\
\hline & Self-employed & 0 & 0 & 1 & 2.40 & & \\
\hline & Clerk & 0 & 0 & 1 & 2.40 & & \\
\hline & Others & 0 & 0 & 1 & 2.40 & & \\
\hline \multirow[t]{4}{*}{ Age } & $\leq 20$ & 1 & 2.90 & 1 & 2.40 & 0.336 & 0.953 \\
\hline & $21-40$ & 24 & 68.60 & 26 & 63.40 & & \\
\hline & $41-60$ & 9 & 25.70 & 13 & 31.70 & & \\
\hline & $>60$ & 1 & 2.90 & 1 & 2.40 & & \\
\hline \multirow[t]{3}{*}{ History of imprisonment } & Once & 15 & 42.90 & 18 & 43.90 & 0.009 & 0.995 \\
\hline & Twice & 14 & 40 & 16 & 39 & & \\
\hline & $\geq$ Three times & 6 & 17.10 & 7 & 17.10 & & \\
\hline \multirow[t]{2}{*}{ Place of residence } & Native & 34 & 97.10 & 41 & 100 & 1.18 & 0.276 \\
\hline & non- Native & 1 & 2.90 & 0 & 0 & & \\
\hline \multirow[t]{4}{*}{ Education } & Primary School & 2 & 5.70 & 0 & 0 & 4.95 & 0.175 \\
\hline & High School & 23 & 65.70 & 30 & 56.60 & & \\
\hline & Diploma & 8 & 22.90 & 11 & 26.80 & & \\
\hline & University Education & 2 & 5.70 & 0 & 0 & & \\
\hline \multirow[t]{4}{*}{ Marital status } & Single & 1 & 2.90 & 0 & 0 & 2.51 & 0.473 \\
\hline & Married & 27 & 77.10 & 34 & 82.90 & & \\
\hline & Divorced & 4 & 11.40 & 2 & 4.90 & & \\
\hline & Widow & 3 & 8.60 & 5 & 12.20 & & \\
\hline \multirow[t]{2}{*}{ Prison term)Year) } & $1-2$ Years & 12 & 34.30 & 13 & 31.70 & 0.570 & 0.812 \\
\hline & $\geq 3$ & 23 & 65.70 & 28 & 68.30 & & \\
\hline
\end{tabular}

stage, the mean score of self-esteem in the intervention group $(22 \pm 2.52)$ was significantly higher than that of the control group $(8.92 \pm 4.04)(p=0.001, t=17.15)$. In other words, the intervention group members were at the low level of self-esteem prior to the intervention, but after attending the educational classes, their self-esteem increased into the moderate level, which indicates the significant effect of the intervention (Table 3).

The covariance analysis test to control the impact of pretest on the self-esteem of women prisoners are

Table 3 The pretest and posttest scores of the control and intervention groups

\begin{tabular}{llll}
\hline Groups & $\begin{array}{l}\text { Pre test } \\
\mathrm{M} \pm \mathrm{SD}\end{array}$ & $\begin{array}{l}\text { Post test } \\
\mathrm{M} \pm \mathrm{SD}\end{array}$ & $\begin{array}{l}\text { Statistic } \\
\mathrm{t}^{\mathrm{a}} \& \mathrm{p}\end{array}$ \\
\hline Intervention & $11.8 \pm 4.67$ & $22.00 \pm 2.52$ & $\begin{array}{l}t=-12.15 \\
P=0.001\end{array}$ \\
Control & $7.97 \pm 4.52$ & $8.92 \pm 4.04$ & $t=-2.79$ \\
& & & $P=0.008$ \\
Statistic $t^{\mathrm{b}} \& p$ & $t=3.61$ & $t=17.5$ & \\
& $P=0.001$ & $P=0.001$ & \\
\hline
\end{tabular}

${ }^{\text {a Paired-t-test, }}{ }^{\text {bindependent-t-test }}$ presented in Table 4. These results confirmed the results in Table 3.

\section{Discussion}

The purpose of this study was to investigate the effect of TA group-training on the self-esteem of imprisoned women. The results showed that the majority of female prisoners were at low levels of self-esteem before implementing the group-training program, which is consistent with the findings of many studies.

For example, a study among the addicted female prisoners in South of Iran represented that most prisoners had low self-esteem [6]. Arefi reported that female prisoners, especially those with commission crimes, had low self-esteem [26].The similarity of these results with those of the present study can be due to the same research population and data collection tools.

Furthermore, a reason for the low level of self-esteem among the imprisoned women can be attributed to the prison conditions and environment. In addition, the prisoners' isolation and being away from their families, fear of rejection in society, and lack of social protection during and after their sentence are among some other 
Table 4 Summary of covariance analysis for the control and intervention groups

\begin{tabular}{llllll}
\hline Variable & Type II sum of square & Df & Mean square & $F$ & $p$-value \\
\hline Corrected model & 3543.22 & 2 & 1771.66 & 233.20 & 210.69 \\
Intercept & 1600.57 & 1 & 1600.57 & 41.62 & $<0.001$ \\
Pre-test & 316.21 & 1 & 316.21 & 272.22 & $<0.001$ \\
Group & 2068.05 & 1 & 2068.05 & $<0.001$ \\
Error & 554.56 & 73 & 7.59 & $<0.001$ \\
\hline
\end{tabular}

effective factors. Alavi showed that Iranian female prisoners had a moderate level of self-esteem. Alavi also introduced low self-esteem as a predictive factor of drug abuse, robbery, and prostitution [27]. Moreover, Kamoyo reported that self-esteem was at a moderate level among the Kenyan female prisoners [28]. The discrepancy between results of the above-mentioned studies and the present study can be probably due to the different cultures of various societies in accepting women, especially female prisoners as well as the different data collection tools.

Results of our study indicated that TA group-training significantly improved the self-esteem of intervention group from the "low" level to the "moderate" Level. Unfortunately, no published study has ever examined the effect of TA group-training as a strategy to improve selfesteem and psychological well-being of the imprisoned women with mental health issues.

Other studies reported TA as an effective reconsideration method in life, which helps the individuals to feel valuable and solve their problems successfully $[16,17$, 29]. Another study on the impact of TA group-training indicated improvement of the self-confidence and the ability to endure failures [18] among members of the intervention group. In several studies, participants reported more success in family life and social relationships [19], reduced mental and psychological stresses [30], increased self-esteem, better control of personal conflicts, and more decisiveness in achieving the goals and ideals [31].The results of a study by Riaz et al. showed that cognitive behavioral therapy (CBT) group programs increased the prisoners' self-acceptance and self-admission and reduced their risky behaviors [32].Furthermore, Khodayarifard et al. conducted the individual and group (combined) cognitive-behavioral interventions and showed improvement in the psychological well-being of the prisoners. Finally, they concluded that these strategies increased the female prisoners' self-efficacy and self-esteem [3].Perhaps, the similarity between the results of these studies can be due to similar intervention methodology and participation in the group discussion. In group therapy sessions, participants are exposed to other participants' experiences and contributions. Therefore, they start to analyze and scrutinize their own problems. In addition, the inmates can benefit from other individuals' opinions and discuss about their problems.

We also found that the imprisoned women in Iran were highly aware of their own low self-esteem and had a tendency to express it through avoidance behaviors. These participants used more emotion-focused than problem-focused coping strategies to overcome their low self-esteem (e.g., active coping, planning, and instrumental support).

Considering that female prisoners in Iran suffer from low self-esteem, which leads into their avoidance behaviors, special group programs, such as TA trainings should be conducted for them by specialties. Consequently, the female prisoners can adapt themselves to the conditions in the community and return to their families by self-acceptance and self-admission.

Our study had a number of limitations. First, the imprisoned women had short-term leaves, family visits, communication with counselors, clinical psychologists, and social workers in prison. These factors could affect the results, but were out-of-control. Second, we could not find a precise instrument to assess the self-esteem of the imprisoned women, therefore, RSES was used. Third, the researchers had access to the prisoners for only 3 months and could conduct only one follow-up 1 month after theintervention. One month is a very short period to assess the impact of TA on a complex behavior such as self-estem. Fourth, the therapist was not permitted to conduct the therapeutic sessions in a separate room. The only available space was a room next to the jailer's office. Furthermore, some security staff attended the ongoing sessions. These factors disturbed the privacy of the intervention group. Fifth, the results might have changed in the case that the control group received some kinds of training, such as strengthening the back muscles or excersizing. Sixth, since the differnce between the two groups was significant at the pre-test with regard to the self-esteem scores, future researchers are recommneded to select participants based on their pretest mean scores of self-esteem, instead of a random allocation to the intervention and control groups. In this way, both groups would have women with comparable mean scores.

Therefore, further research are suggested using a valid and reliable tool to assess the self-esteem of the 
imprisoned women. Moreover, longitudinal studies should be conducted bycontroling the confounding variables.

\section{Conclusion}

Results of the present study showed that TA had a significantly positive effect on the imprisoned women in the intervention group. Therefore, prison managers are recommended to conduct TA group-trainings with the help of psychologists and psychiatric nurses to strengthen self-esteem of the imprisoned women.

Rehabilitative programmers are also suggested to employ the self-esteem strategy in prisons to improve the prisoners' self-esteem. Furthermore, the prison environment should be modified to allow for more frequent presence of social support groups. In this regard, we recommend other researchers to carry out quantitative and qualitative studies on the effective strategies to overcome the barriers against self-esteem among female prisoners. Future studies can also examine the effect of TA grouptraining on other psychological aspects of the imprisoned women in various cultures and contexts.

\section{Supplementary information}

Supplementary information accompanies this paper at https://doi.org/10. 1186/s40359-019-0369-x.

Additional file 1. Rosenberg Self-Esteem Scale

\section{Abbreviations}

RSES: Rosenberg's self-esteem scale; TA: Transactional analysis

\section{Acknowledgments}

The authors appreciate the prison officials and all women who participated in this study. We also appreciate Mrs. Chakameh Navard and Mr. Fathi, the clinical psychologists, who cooperated with us during this study.

\section{Authors' contributions}

MT, SM, JF, and BP contributed in the research design. The data were collected, analyzed, and interpreted by MT and JF. MT organized the group training. MT, SM, JF, and BP contributed equally in composing and approving the final manuscript. All authors read and approve the final version of this manuscript.

\section{Funding}

This research received no specific grant from any funding agencies in the public, commercial, or not-for-profit sectors.

\section{Availability of data and materials \\ The datasets generated and analysed in the present study, are available upon request to the corresponding author after signing appropriate documents in line with ethical application and the decision of the Ethics Committee.}

\section{Ethics approval and consent to participate}

The present research was conducted after obtaining the ethical code (IR.KMU.REC.1395.1670) from the Ethics Committee of Kerman University of Medical Sciences and the clinical trial code (IRCT20170725035289N5) from Iranian Registry of Clinical Trials (IRCT). In order to conduct the study, the first researcher presented an introduction letter to make the necessary coordination with the prison authorities. Later, written consent forms were obtained from the authorities. Prior to data collection, the included participants were provided with a cover letter explaining the purpose of the study and the procedure of data collection. Then, written consent forms were obtained from the participants and they were ensured about confidentiality and anonymity of the data. They were also explained about voluntary participation in the study.

Consent for publication

Not applicable.

\section{Competing interests}

The authors declare that they have no competing interests.

\section{Author details}

${ }^{1}$ Student Research Committee, Department of Nursing, School of Nursing and Midwifery, Shiraz University of Medical Sciences, Shiraz, Iran. ${ }^{2}$ Nursing Research Center, Kerman University of Medical Sciences, Kerman, Iran. ${ }^{3}$ Department of Psychiatric Nursing, School of Nursing and Midwifery, Kerman University of Medical Sciences, Haft-Bagh Highway, PO Box:

7716913555, Kerman, Iran. ${ }^{4}$ Department of pediatric and neonatal nursing, School of Nursing and Midwifery, Tehran University of Medical Sciences, Tehran, Iran

Received: 30 March 2019 Accepted: 24 December 2019

Published online: 13 January 2020

\section{References}

1. Fajarwatia A, Tyas Wulan Meia E, Hasanatia S, Saria IM. The productive and reproductive activities of women as form of adaptation and post-disaster livelihood strategies in Huntap Kuwang and Huntap Plosokerep. Soc Behav Sci. 2016;227:370-7.

2. Heras Santos JL. Women's reformatories and prisons in the early modern age: morality, welfare and repression of women in the 17th and 18th century. Soc Behav Sci. 2014;161:176-83.

3. Khodayarifard M, Shokoohi-Yekta M, Hamot G. Effects of Individual and Group Cognitive-Behavioral Therapy for Male Prisoners in Iran, vol. 54; 2009.

4. Ticusan M. Low self-esteem, premise of depression appearance at adolescents. Soc Behav Sci. 2012;69:1590-3.

5. Phillips D, Hagan T, Bodfield E, Woodthorpe K, Grimsley M. Exploring the impact of group work and mentoring for multiple heritage children's self-esteem, wellbeing and behaviour. Health Soc Care Community. 2008;16(3):310-21.

6. Torkaman M, Miri S, Farokhzadian J. Relationship between adaptation and selfesteem in addicted female prisoners in the south east of Iran. Int J Adolesc Med and Health. 2018. https://doi.org/10.1515/ijamh-2017-0168. [Epub ahead of print]. Retrieved January 7, 2020, from https://www.ncbi.nIm.nih.gov.

7. Liu JY, Yang JP, Yang Y, Liu YH. The relationships among perceived organizational support, intention to remain, career success and self-esteem in Chinese male nurses. Int J Nursing Sci. 2015;2:389-93.

8. Ghasimbaklo U, Mohammadyari G, Mahmodzadeh M, Mohammadzadeghan $\mathrm{R}$, Mokhtari M. The relationship of social support and self-esteem with recidivism among prisoners. J Res Health. 2014;4:818-26.

9. Maltesea A, Alesia M, Giuseppa A. Self-esteem, defensive strategies and social intelligence in the adolescence. Soc Behav Sci. 2012;69:2054-60

10. Liu H, Zhang X, Chang R, Wang W. A research regarding the relationship among intensive care nurses' self-esteem, jobsatisfaction and subjective well-being. Int J Nursing Sci. 2017:4(3):291-5.

11. Bąk-Sosnowska M, Naworska B, Owczarek A, et al. Coping with overweight strategies, self-esteem and body-esteem in the context of transactional analysis. Psychiatr Pol. 2014;48(3):477-87.

12. Ciucur D. The Ego states and the "big five" personality factors. Soc Behav Sci. 2012;78:581-5.

13. Nayeria A, Lotfib M, Noorani M. The effectiveness of group training of transactional analysis on intimacy in couples. Soc Behav Sci. 2014;152:1167-70.

14. Hadži-Pešica M, Mitrovica M, Brajovic Carb K, Stojanovic D. Personality of alcohol addict according to the theory of transactional analysis. Soc Behav Sci. 2014;127:230-4.

15. Yonder Ertem M, Kececi A. Ego states of nurses working in psychiatric clinics according to transactional analysis theory. Pak J Med Sci. 2016;32(2):485-90.

16. Temple S. Celebrating functional fluency and its contribution to transactional analysis theory. Trans Anal J. 2015;45(1):10-22. 
17. Widdowson M. Transactional analysis psychotherapy for a case of mixed anxiety \& depression: a pragmatic adjudicated case study - 'Alastair. Int J Transact Anal Res. 2014;5(2):66-76.

18. Ciucur D. A transactional analysis group psychotherapy Programme for improving the qualities and abilities of future psychologists. Soc Behav Sci. 2013;78:576-80.

19. Kovacevic I, Panic B, Vujosevic M, Kuzmanovic M. Application of transactional analysis in bullwhip effect analysis. Amfiteatru Econ. 2013;33:210-23.

20. Beekum SV. A new formulation of transactional analysis theory in the field of organizations. Sage J. 2015;45(3):167-78.

21. Forghani M, Abadi BAGH. The Effect of Group Therapy With Transactional Analysis Approach on Emotional Intelligence, Executive Functions and Drug Dependency. Iran J Psychiatry Behav Sci. 2016;10(2):e2423.

22. Ramiro MT, Teva I, Bermúdez MP, Buela-Casal G. Social support, self-esteem and depression: relationship with risk for sexually transmitted infections/HIV transmission. Int J Clin Health Psychol. 2013;13(3):181-8.

23. Rosenberg M. Society and the adolescent self-image. New Jersey: Princeton University Press; 2015. Retrieved January 7, 2020, from https://press. princeton.edu.

24. Rajabi G, Bohlol N. Assess the reliability and validity of self-esteem in students' Vznbrg in the first year should be Chamran University. Psychol Educ Res. 2008:3(2):33-48 [in persian].

25. Kafi M, Melazadeh Esfandiani R, Noori Khajavi M, Salehi I. Effectiveness of group therapy by cross-sectional analysis method on marital adjustment and prevention of recurrence of detoxified persons. New Psychol Res. 2011; 6(23):111-32 (Psychology, University of Tabriz) [in persian].

26. Arefi M. The comparison of psychological factors (locus of control, selfesteem, and personality disorders) between normal and prisoner women with emphasis on prostitute women. J Psychol Stud. 2010;6(4):125-46.

27. Alavi HR. The role of self-esteem in tendency towards drugs, theft and prostitution. Addict Health. 2011;3(3-4):119-24.

28. Kamoyo J. Effects of Imprisonment on Self-Esteem Among Female Inmates in Selected Prisons in Kenya. Eur Sci J. 2018;14(17):165.

29. Ciucur D, Pîrvuț AF. The effects of a transactional analysis training programme on team leadership factors in automotive industry. Procedia Soc Behav Sci. 2012;33:667-71.

30. Widdowson M. TA treatment of depression - a hermeneutic single-case efficacy design study - 'Denise'. Int J Transact Anal Res. 2012;3(2):3-14.

31. Neac $u$ V. The Efficiency of a Cognitive-Behavioral Program in Diminishing the Intensity of Reactions to Stressful Events and Increasing Self-Esteem and Self-Efficiency in the Adult Population. Soc Behav Sci. 2013;78:380-4.

32. Riaz R, Agha S. Efficacy of cognitive behavior therapy with deliberate selfharm in incarcerated women. Pak J Psychol Res. 2011;27(1):21-35.

\section{Publisher's Note}

Springer Nature remains neutral with regard to jurisdictional claims in published maps and institutional affiliations.

Ready to submit your research? Choose BMC and benefit from:

- fast, convenient online submission

- thorough peer review by experienced researchers in your field

- rapid publication on acceptance

- support for research data, including large and complex data types

- gold Open Access which fosters wider collaboration and increased citations

- maximum visibility for your research: over $100 \mathrm{M}$ website views per year

At $\mathrm{BMC}$, research is always in progress.

Learn more biomedcentral.com/submissions 